05,12

\title{
Магнитная восприимчивость нанокомпозитных редкоземельных титанатов в переменных полях
}

\author{
(С) А.Б. Ринкевич, Д.В. Перов \\ Институт фризики металлов им. М.Н. Михеева УрО РАН, \\ Екатеринбург, Россия \\ E-mail: rin@imp.uran.ru
}

Поступила в Редакцию 15 февраля 2019 г.

В окончательной редакции 18 мая 2020 г.

Принята к публикации 20 июля 2020 г.

\begin{abstract}
Выполнены экспериментальные исследования магнитной восприимчивости нанокомпозитных редкоземельных титанатов при низких температурах в интервале частот от 1 до $10 \mathrm{kHz}$. Объектами исследования были нанокомпозиты на основе опаловых матриц, в межсферические полости которых помещены частицы титанатов $\mathrm{Gd}_{2} \mathrm{Ti}_{2} \mathrm{O}_{7}, \mathrm{Yb}_{2} \mathrm{Ti}_{2} \mathrm{O}_{7}, \mathrm{Dy}_{2} \mathrm{Ti}_{2} \mathrm{O}_{7}$ и $\mathrm{Dy}_{2} \mathrm{Si}_{2} \mathrm{O}_{7}$ размером до $60 \mathrm{~nm}$. Измерены частотные зависимости $\mathrm{AC}$ восприимчивости нанокомпозитов с частицами $\mathrm{Gd}_{2} \mathrm{Ti}_{2} \mathrm{O}_{7}, \mathrm{Dy}_{2} \mathrm{Ti}_{2} \mathrm{O}_{7}$ и $\mathrm{Dy}_{2} \mathrm{Si}_{2} \mathrm{O}_{7}, \mathrm{Yb}_{2} \mathrm{Ti}_{2} \mathrm{O}_{7}$ в интервале температур от 2 до $20 \mathrm{~K}$. В области частот свыше $1 \mathrm{kHz}$ частотная зависимость всех исследованных нанокомпозитов удовлетворительно описывается моделью релаксирующих осцилляторов и аппроксимируется по формуле Дебая. Однако для описания частотной зависимости восприимчивости от 1 до $10 \mathrm{kHz}$ требуется модель с двумя временами релаксации.
\end{abstract}

Ключевые слова: нанокомпозиты, редкоземельные титанаты, магнитная восприимчивость.

DOI: $10.21883 /$ FTT.2020.12.50210.350

\section{1. Введение}

Благодаря реализации фрустрированных магнитных состояний и особенно осуществлению состояния спинового льда („spin ice“), редкоземельные титанаты со структурой пирохлора привлекли к себе пристальное внимание. Эти титанаты имеют общую химическую формулу $R_{2} \mathrm{Ti}_{2} \mathrm{O}_{7}$, где $R-$ трехвалентный ион редкоземельного металла. Эти ионы занимают позиции в вершинах тетраэдров в структуре пирохлора, причем магнитные моменты четырех ионов, расположенных в одном тетраэдре, подчиняются правилу спинового льда, а именно: два момента направлены вовнутрь тетраэдра, а два другие - наружу. Состояния магнитных моментов в решетке оказываются вырожденными, и в основном состоянии такой системы энтропия оказывается ненулевой, так что большое число состояний имеют одинаковую энергию [1]. Фрустрация магнитных моментов вызвала повышенный интерес ко всему классу титанатовпирохлоров. Состояние классического спинового льда осуществляется при низких температурах в титанатах гольмия и диспрозия. Не исключено, что состояние квантового спинового льда реализуется в титанате иттербия. На кривых намагничивания, измеренных при температурах ниже $\sim 1 \mathrm{~K}$, в состоянии спинового льда наблюдаются плато [2], а при увеличении скорости намагничивания наблюдаются неустойчивости [3]. Явления неустойчивостей нашли объяснение в представлении об управляемом полем движении так называемых „магнитных монополей“ [4]. Из частотной зависимости магнитной восприимчивости, в частности, из ее высокочастотного или адиабатического предельного значения можно получить оценки подвижности монополей. Коллективное движение магнитных монополей в спиновом льде $\mathrm{Dy}_{2} \mathrm{Ti}_{2} \mathrm{O}_{7}$ оказывает влияние на частотную зависимость восприимчивости [5]. Эти необычные свойства привлекли внимание к исследованию восприимчивости титанатов в переменных (АС) полях.

Разумеется, эти экзотические свойства спиновых систем проявляются при очень низких температурах. Исследование статической (DC) восприимчивости нескольких редкоземельных титанатов типа $R_{2} \mathrm{Ti}_{2} \mathrm{O}_{7}$ при температурах выше $2 \mathrm{~K}$ было выполнено в [6]. Там было проведено сопоставление магнитных и оптических свойств титанатов, а также проведен анализ температурной зависимости DC восприимчивости, исходя из их электронной структуры. В работе [7] проведено исследование магнитных свойств объемных образцов $\mathrm{Dy}_{2} \mathrm{Ti}_{2} \mathrm{O}_{7}$, причем особое внимание было уделено процессам „замерзания“сппинов. Ход этих процессов согласуется с представлением о спиновом стекле, которое определяется геометрической фрустрацией магнитных монополей.

Магнитные свойства нанокомпозитных образцов редкоземельных титанатов были изучены в [8]. Нанокомпозитные образцы получены внесением редкоземельных титанатов в межсферические полости опаловых матриц. Было установлено, что в нанокомпозитах с частицами $\mathrm{Yb}_{2} \mathrm{Ti}_{2} \mathrm{O}_{7}, \mathrm{Dy}_{2} \mathrm{Ti}_{2} \mathrm{O}_{7}, \mathrm{Gd}_{2} \mathrm{Ti}_{2} \mathrm{O}_{7}$ и $\mathrm{Er}_{2} \mathrm{Ti}_{2} \mathrm{O}_{7}$ при температурах от 2 до $\sim 30 \mathrm{~K}$ присутствует магнитное упорядочение. При этих же условиях оказалось, что магнитное упорядочение отсутствует в нанокомпозитных образцах с частицами $\mathrm{Pr}_{2} \mathrm{Ti}_{2} \mathrm{O}_{7}, \mathrm{Nd}_{2} \mathrm{Ti}_{2} \mathrm{O}_{7}$. Сопоставление магнитных свойств нанокомпозитных и объемных 
титанатов $\mathrm{Ho}_{2} \mathrm{Ti}_{2} \mathrm{O}_{7}$ и $\mathrm{Dy}_{2} \mathrm{Ti}_{2} \mathrm{O}_{7}$ проведено в [9], а влияние допирования висмутом на магнитные свойства объемных титанатов $\mathrm{Ho}_{2} \mathrm{Ti}_{2} \mathrm{O}_{7}$ и $\mathrm{Yb}_{2} \mathrm{Ti}_{2} \mathrm{O}_{7}$ исследовано в [10]. Исследование магнитной восприимчивости в переменных полях было выполнено в объемных образцах титанатов $\mathrm{Dy}_{2} \mathrm{Ti}_{2} \mathrm{O}_{7}[11,12]$ и $\mathrm{Ho}_{2} \mathrm{Ti}_{2} \mathrm{O}_{7}$ [13]. В этих работах показано, что в исследованных титанатах при низких температурах существуют два механизма релаксации, и для описания частотной и температурной зависимостей восприимчивости требуется ввести два времени релаксации спинов. Согласно [12], одно из этих времен соответствует медленной релаксации. Этот процесс наблюдается в $\mathrm{Dy}_{2} \mathrm{Ti}_{2} \mathrm{O}_{7}$ при температурах $\sim 2 \mathrm{~K}$ и ниже и соответствует сильно вырожденному основному состоянию. Второе время релаксации наблюдается в частотных зависимостях АС восприимчивости как при низких, так и более высоких температурах $\sim 10 \mathrm{~K}$.

В этой статье рассмотрена АС восприимчивость нанокомпозитных образцов редкоземельных титанатов. Для исследования выбраны нанокомпозиты, обладающие магнитным упорядочением при низких температурах. AC восприимчивость исследована на частотах от 1 до $10 \mathrm{kHz}$ при температурах от 2 до $20 \mathrm{~K}$. Измерены частотные зависимости восприимчивости и проведена аппроксимация этих зависимостей по формулам КоулКоула с одним и с двумя временами релаксации.

\section{2. Образцы нанокомпозитных редкоземельных титанатов и методы эксперимента}

Кристаллическая решетка титанатов типа $R_{2} \mathrm{Ti}_{2} \mathrm{O}_{7}$ со структурой пирохлора описывается пространственной группой $F d \overline{3} m$. Ионы трехвалентного редкоземельного

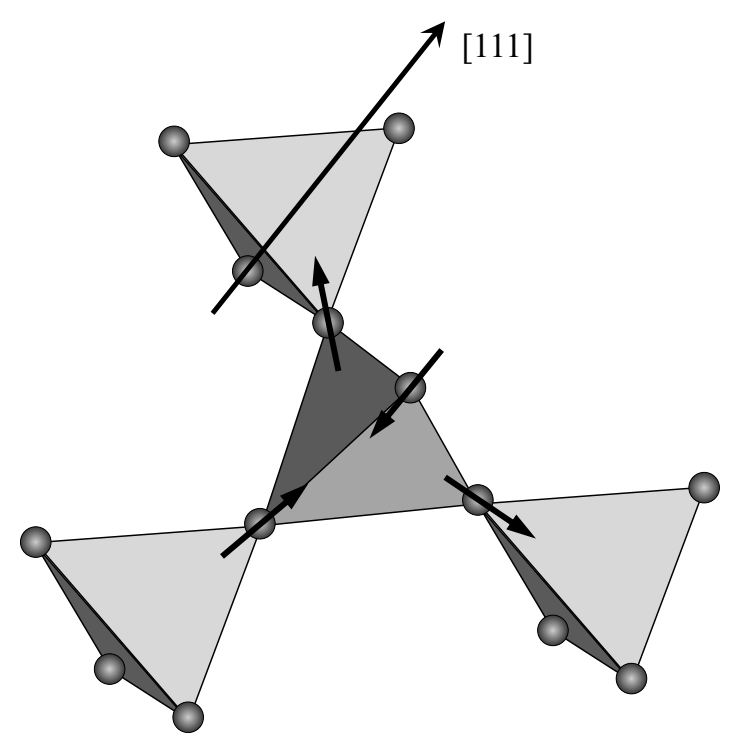

Рис. 1. Схематическое изображение структуры титанатов пирохлоров. Указаны положения ионов РЗ-элементов и возможное направление магнитных моментов.
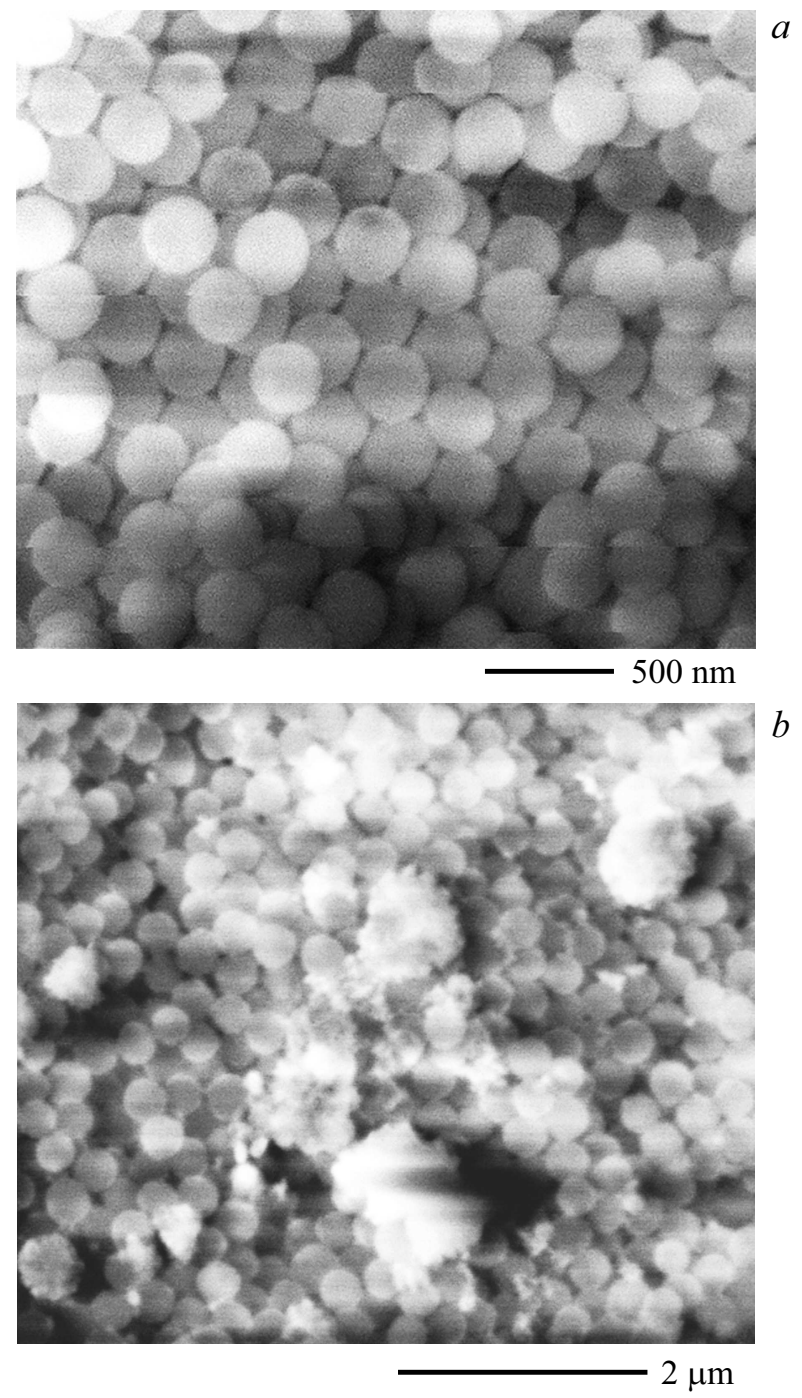

Рис. 2. Структура опаловой матрицы $(a)$ и нанокомпозита с частицами $\mathrm{Yb}_{2} \mathrm{Ti}_{2} \mathrm{O}_{7}(b)$, полученная с помощью сканирующего электронного микроскопа Quanta-200.

металла расположены в вершинах тетраэдров, см. рис. 1 . Для анализа магнитных свойств расположение этих ионов наиболее важно. Основой для приготовления нанокомпозитных образцов были выбраны опаловые матрицы. Это плотно упакованные структуры субмикронных сфер из аморфной двуокиси кремния, см. рис. 2, $a$.

Выбор искусственных опалов в качестве матрицы нанокомпозита вызван несколькими обстоятельствами. Пустая опаловая матрица обладает очень малой восприимчивостью, так что магнитные свойства нанокомпозита почти полностью определяются свойствами внесенных частиц. Размер внесенных частиц ограничен максимальным размером полостей между субмикронными сферами. Частицы в этом нанокомпозите расположены приблизительно периодически. Способ приготовления опаловых матриц со сферами диаметром 260-270 nm описан в [14]. Для внесения частиц титанатов используются растворы прекурсоров - солей, содержащих 
редкоземельные элементы и титан. Образец пропитывается раствором прекурсора, и после прохождения химической реакции окислы металлов выпадают в осадок. После реакции между окислами титана и редкоземельных элементов, происходящей при термической обработке, образуются частицы желаемого состава. Для увеличения объема внесенного вещества процедура пропитки повторялась пять раз с последующей термической обработкой. Температура термической обработки была выбрана $T=900^{\circ} \mathrm{C}$, достаточная для реакции получения титаната, но при которой еще не происходит подплавления субмикронных сфер из $\mathrm{SiO}_{2}$. Использованные в данной работе нанокомпозитные образцы приготовлены М.И. Самойловичем в ОАО ЦНИТИ „Техномаш“.

Структура нанокомпозита с частицами $\mathrm{Yb}_{2} \mathrm{Ti}_{2} \mathrm{O}_{7}$ показана на рис. 2, $b$. Изображение получено с помощью сканирующего электронного микроскопа Quanta200 при ускоряющем напряжении $20 \mathrm{kV}$ и с увеличением $\times 50000$. Частицы внесенного титаната имеют неправильную форму. Они расположены в межсферических полостях и в неповрежденном образце их размеры не превышают $60 \mathrm{~nm}$. Из-за повторения 5 раз термической обработки в одной полости могут образоваться несколько частиц. Объемная доля частиц в образцах составляет от 5 до $15 \%$.

Фазовый состав нанокомпозитов исследован с применением метода рентгеновской дифрактометрии. На рис. 3 показана дифрактограмма нанокомпозитного образца с частицами $\mathrm{Gd}_{2} \mathrm{Ti}_{2} \mathrm{O}_{7}$. Анализ дифрактограммы с помощью программного комплекса HighScorePlus 4.1 показал, что в состав внесенного вещества входит фаза со структурой $\mathrm{Gd}_{2} \mathrm{Ti}_{2} \mathrm{O}_{7}$ и некоторое количество рутила $\mathrm{TiO}_{2}$. Подобный результат дали и исследования других нанокомпозитов, изученных в работе. Во всех случаях в состав входит редкоземельный титанат со структурой пирохлора и рутил $\mathrm{TiO}_{2}$.

Измерения кривой намагничивания и петли гистерезиса нанокомпозитов были выполнены для характеризации

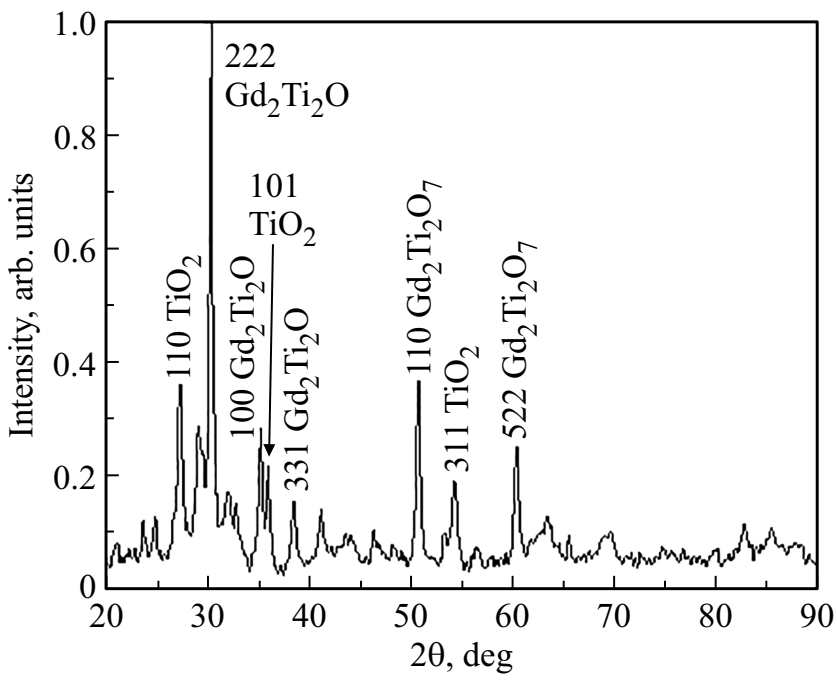

Рис. 3. Рентгенограмма образца нанокомпозита с частицами $\mathrm{Gd}_{2} \mathrm{Ti}_{2} \mathrm{O}_{7}$.
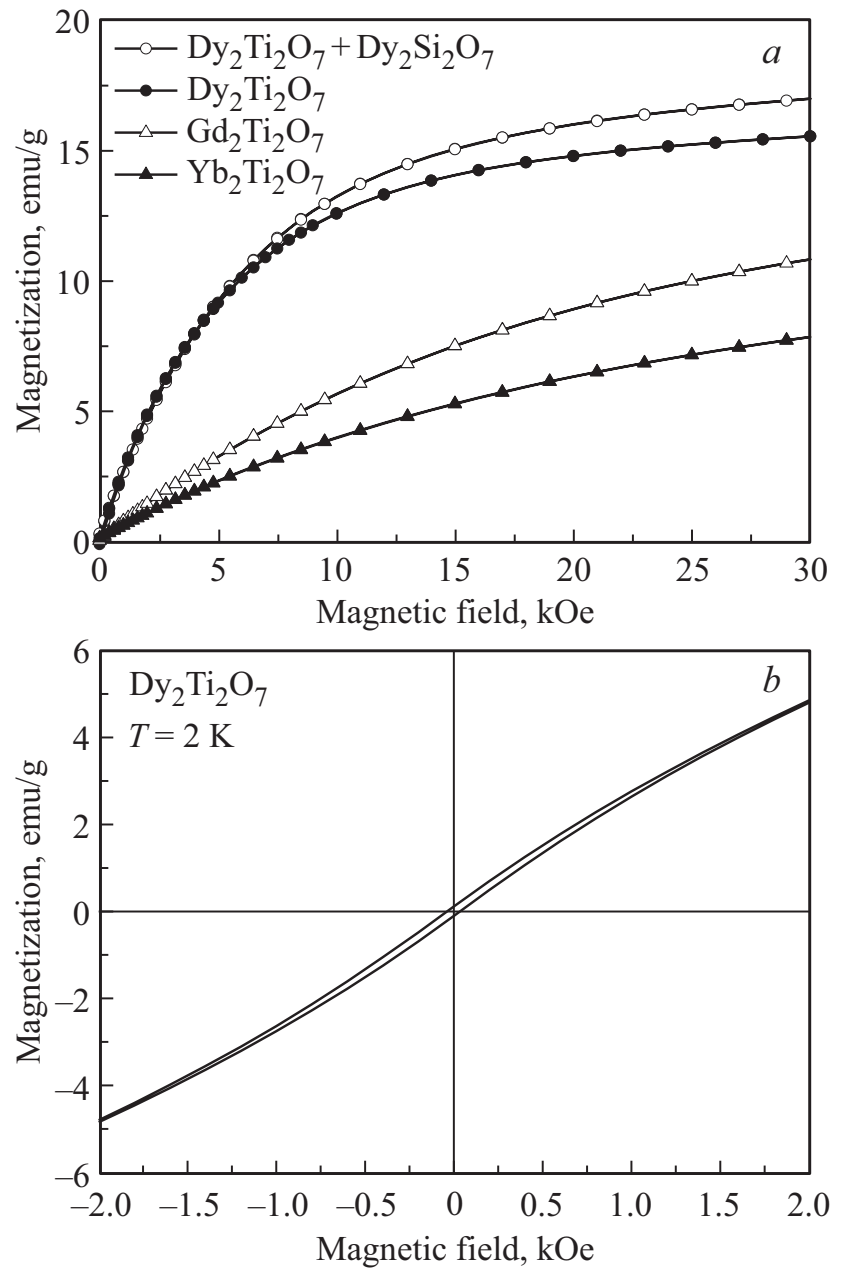

Рис. 4. Серия кривых намагничивания нанокомпозитов при температуре $T=2 \mathrm{~K}(a)$; петля гистерезиса нанокомпозита с частицами $\mathrm{Dy}_{2} \mathrm{Ti}_{2} \mathrm{O}_{7}(b)$.

магнитного состояния. Как известно, объемные редкоземельные титанаты-пирохлоры в состоянии спинового льда не обладают дальним магнитным порядком. Однако в [8] для нескольких нанокомпозитных титанатов были обнаружены петли гистерезиса при температурах от 2 до $30 \div 50 \mathrm{~K}$, что свидетельствует о магнитном упорядочении. Упорядочение наблюдалось для нескольких нанокомпозитов, в том числе для нанокомпозита с частицами диспрозия, обладающего большим магнитных моментом и для объемных образцов которого осуществляется состояние спинового льда.

Кривые намагничивания нанокомпозитных титанатов, измеренные на сквид-магнитометре MPMS-5XL при температуре $T=2 \mathrm{~K}$, показаны на рис. 4, $a$. Они имеют вид, типичный для нанокомпозитных титанатов. В полях до $30 \mathrm{kOe}$ для нанокомпозитов с частицами $\mathrm{Yb}_{2} \mathrm{Ti}_{2} \mathrm{O}_{7}$ и $\mathrm{Gd}_{2} \mathrm{Ti}_{2} \mathrm{O}_{7}$ полное магнитное насыщение не достигается. Замещение ионов $\mathrm{Ti}$ на $\mathrm{Si}$, произошедшее в одном из образцов в результате термической обработки, не повлияло заметно на намагниченность. На рис. $4, b$ показана петля гистерезиса, измеренная при температуре $2 \mathrm{~K}$ 
в нанокомпозите с частицами $\mathrm{Dy}_{2} \mathrm{Ti}_{2} \mathrm{O}_{7}$. Петля гистерезиса существует и выглядит узкой, т.е. остаточная намагниченность $M_{r}$ намного меньше намагниченности насыщения $M_{s}, M_{r} \ll M_{s}$ и коэрцитивная сила $H_{c}$ много меньше поля насыщения $H_{s}, H_{c} \ll H_{s}$. В [8] было установлено одно интересное свойство петель гистерезиса рассматриваемых нанокомпозитов. Спадающие ветви петель гистерезиса, измеренные при разных температурах, пересекаются в одной точке. В этой точке в некотором интервале температур DC намагниченность будет лишь слабо зависеть от температуры. Например, в [8] приведен пример нанокомпозита с частицами $\mathrm{Yb}_{2} \mathrm{Ti}_{2} \mathrm{O}_{7}$, у которого от температуры слабо зависит остаточная намагниченность $M_{r}$. Отметим, что область слабой температурной зависимости АС восприимчивости наблюдалась для объемного титаната $\mathrm{Dy}_{2} \mathrm{Ti}_{2} \mathrm{O}_{7}$ на частоте $10 \mathrm{kHz}$ во внешнем магнитном поле $H=6.88 \mathrm{kOe}$ [15].

\section{3. Магнитная восприимчивость в переменных полях}

Магнитная восприимчивость нанокомпозитов была измерена в температурном интервале от 2 до $20 \mathrm{~K}$ на частотах от 1 до $10 \mathrm{kHz}$ на установках PPMS-9 и MPMS-5XL. Эти измерения выполнены при амплитуде АC поля $H_{\sim}=4$ Ое. Были измерены частотные зависимости АС восприимчивости $\chi$ при нескольких температурах. Измерения проведены на образцах массой от 30 до $200 \mathrm{mg}$. В предыдущем разделе было установлено, что намагниченность нанокомпозитов в использованных магнитных полях невелика и не превышает единиц еmu/g. Поэтому форма образца не имеет большого значения. Результаты измерений для нанокомпозита с частицами $\mathrm{Gd}_{2} \mathrm{Ti}_{2} \mathrm{O}_{7}$ показаны на рис. 5. Частотные зависимости действительной $\chi^{\prime}$ и мнимой $\chi^{\prime \prime}$ частей $\mathrm{AC}$ восприимчивости, измеренные при температуре $2 \mathrm{~K}$, показаны на рис. 5, a. Частотные зависимости действительной части восприимчивости для того же нанокомпозита, измеренные при разных температурах, показаны на рис. 5, $b$. Как и следовало ожидать, при понижении температуры восприимчивость возрастает, и ее частотная зависимость становится более выраженной. Частотные зависимости действительной и мнимой частей восприимчивости нанокомпозита с частицами $\mathrm{Dy}_{2} \mathrm{Ti}_{2} \mathrm{O}_{7}+\mathrm{Dy}_{2} \mathrm{Si}_{2} \mathrm{O}_{7}$, измеренные при температуре $T=2 \mathrm{~K}$, приведены на рис. $6, a$. Здесь частотная зависимость выражена сильнее, чем в предыдущем случае. Эти зависимости имеют типичный для редкоземельных титанатов характер [11]. Можно, однако, отметить, что для нашего нанокомпозитного образца максимум на частотной зависимости $\chi^{\prime \prime}$ достигается при $T=2 \mathrm{~K}$ на частоте $\sim 9 \div 10 \mathrm{kHz}$, а в [12] для объемного образца при $T=1.9 \mathrm{~K}$ на частоте $\sim 300-400 \mathrm{~Hz}$. Зависимости действительной части АС-восприимчивости, измеренные в поле $H_{\sim}=4$ Ое при нескольких температурах, для этого нанокомпозита показаны на рис. $6, b$. C понижением температуры величина действительной части восприимчивости увеличивается и ее частотная зависимость усиливается. Для нанокомпозита с частицами
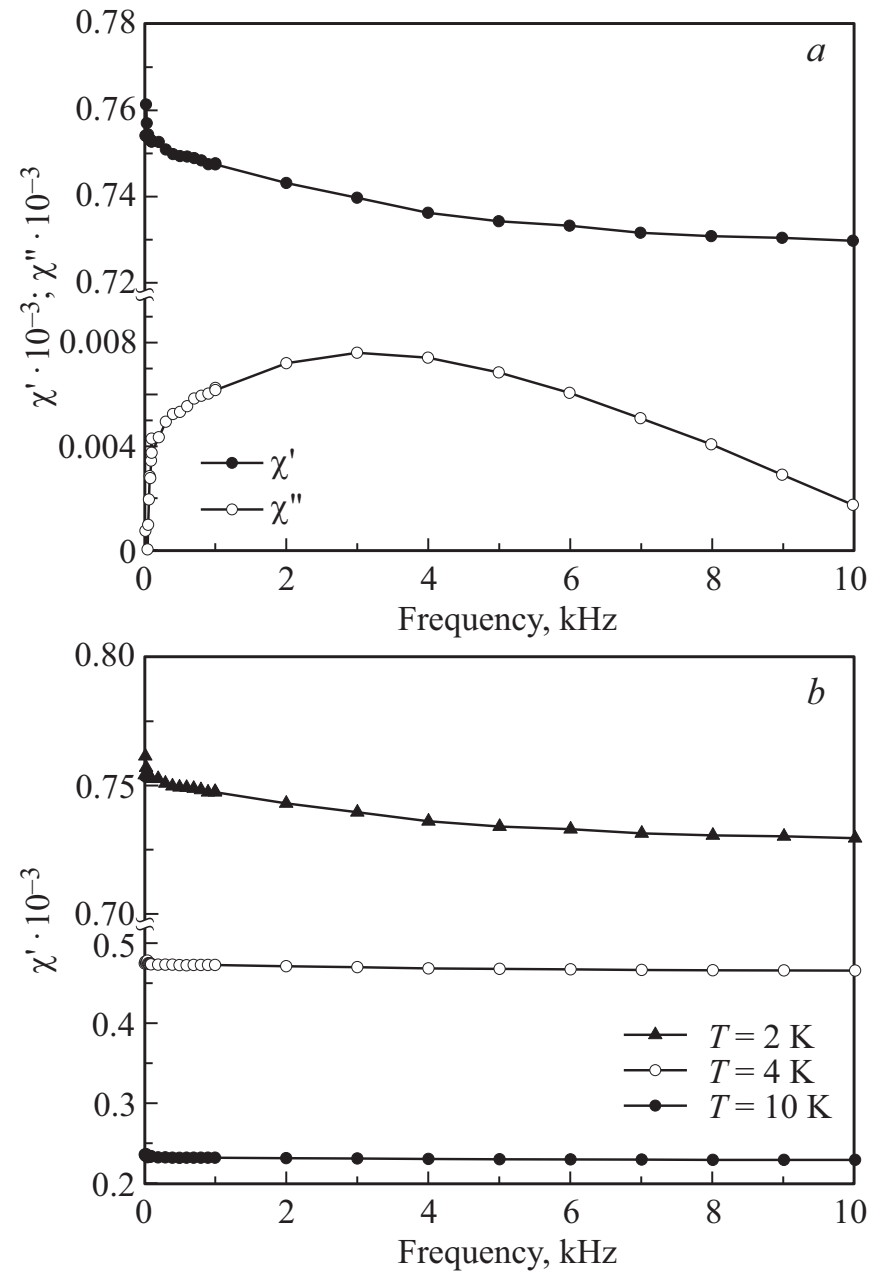

Рис. 5. Частотные зависимости действительной и мнимой частей восприимчивости нанокомпозита с частицами $\mathrm{Gd}_{2} \mathrm{Ti}_{2} \mathrm{O}_{7}$, измеренные при температуре $T=2 \mathrm{~K}(a)$; частотные зависимости действительной части АС восприимчивости этого же нанокомпозита, измеренные при нескольких температурах $(b)$.

$\mathrm{Yb}_{2} \mathrm{Ti}_{2} \mathrm{O}_{7}$ частотная зависимость действительной части восприимчивости выражена слабо.

На рис. 7 показана нормированная зависимость мнимой части магнитной восприимчивости от действительной части, то есть диаграмма Арганда, построенная для нанокомпозита с частицами $\mathrm{Gd}_{2} \mathrm{Ti}_{2} \mathrm{O}_{7}$ в интервале частот от 10 до $10 \mathrm{kHz}$ при температуре $T=2 \mathrm{~K}$. Соотношение между действительной и мнимой частями восприимчивости вытекает из формулы Дебая (1) для релаксирующего осциллятора

$$
\chi(\omega)=\chi^{\prime}(\omega)-i \chi^{\prime \prime}(\omega)=\chi_{\infty}+\frac{\chi_{0}-\chi_{\infty}}{1+i \omega \tau},
$$

где $\omega=2 \pi f-$ круговая частота, $\chi_{0}-$ магнитная восприимчивость при $\omega \rightarrow 0, \chi_{\infty}-$ магнитная восприимчивость в высокочастотном пределе, т.е. адиабатическая восприимчивость, $\tau-$ время релаксации осциллятора. Зависимость $\chi^{\prime \prime}$ от $\chi^{\prime}$, согласно (1), имеет вид полуокружности. Изменения с частотой действительной части восприимчивости на рис. 7 при $T=2 \mathrm{~K}$ 

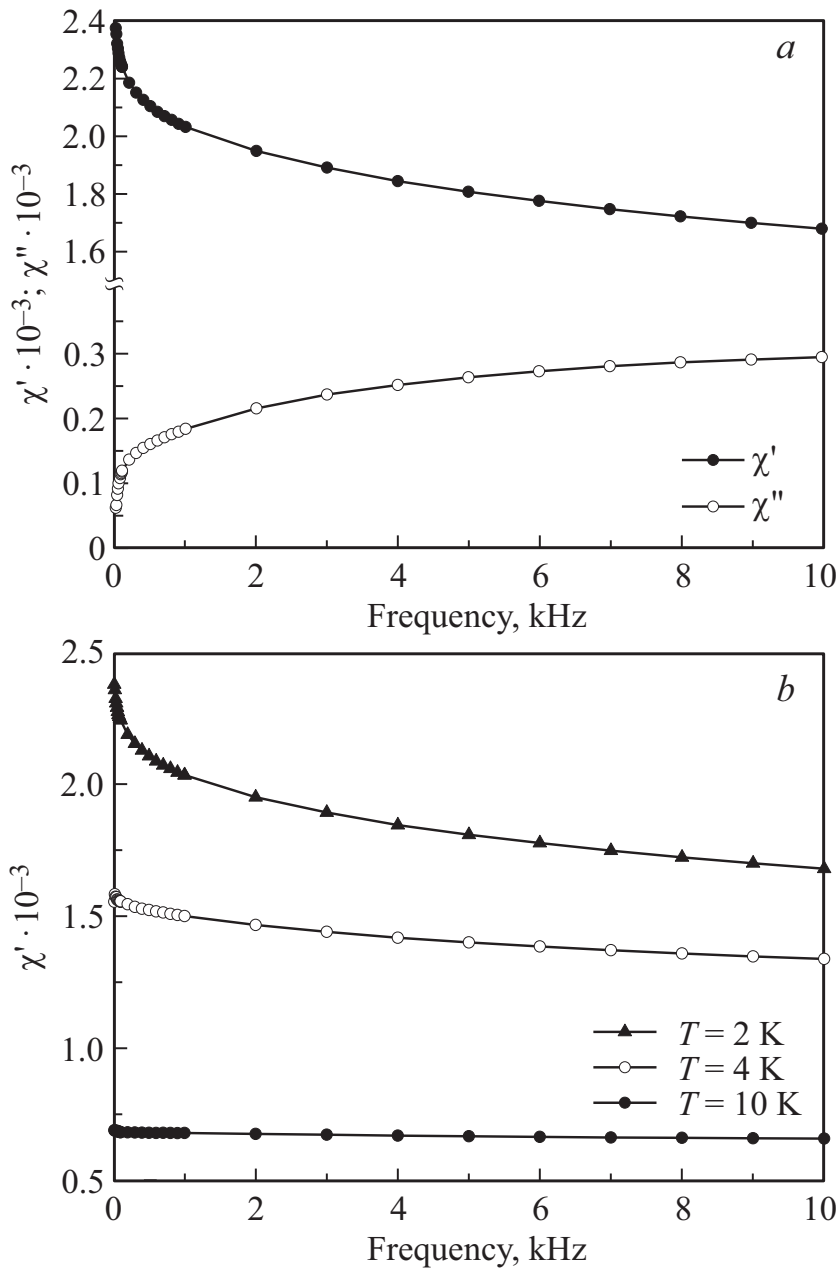

Рис. 6. Частотные зависимости действительной и мнимой частей восприимчивости нанокомпозита с частицами $\mathrm{Dy}_{2} \mathrm{Ti}_{2} \mathrm{O}_{7}$ и $\mathrm{Dy}_{2} \mathrm{Si}_{2} \mathrm{O}_{7}$, измеренные при температуре $T=2 \mathrm{~K}(a)$; частотные зависимости действительной части АС восприимчивости этого же нанокомпозита, измеренные при нескольких температурах $(b)$

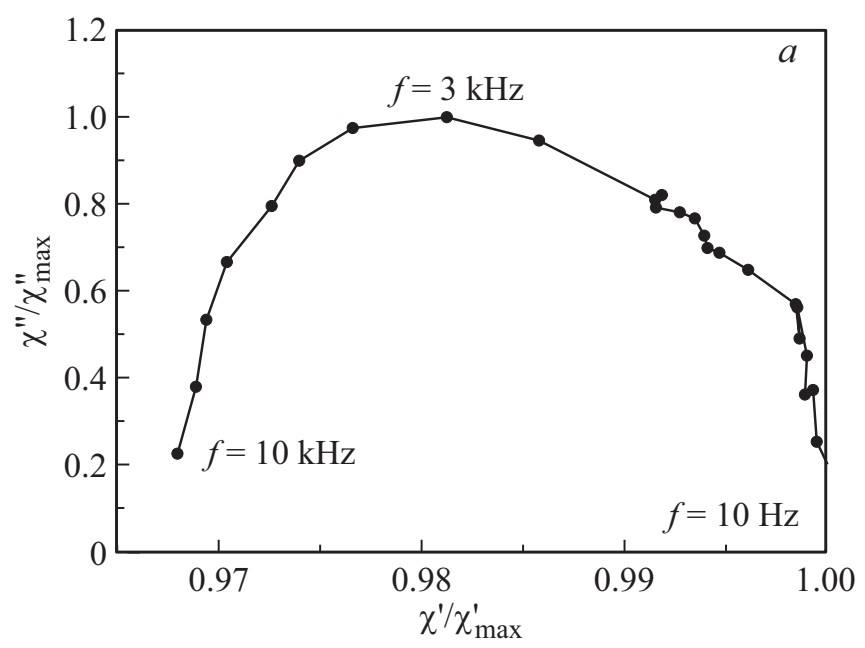

Рис. 7. Диаграмма Арганда для АC магнитной восприимчивости нанокомпозита с частицами $\mathrm{Gd}_{2} \mathrm{Ti}_{2} \mathrm{O}_{7}$ при $T=2 \mathrm{~K}$, построенная в интервале частот от 10 до $10 \mathrm{kHz}$. невелики, всего чуть более 3\%. При более высоких температурах эти изменения еще меньше. Как видно из рис. 7, измеренная зависимость качественно повторяет вид диаграммы Арганда.

\section{4. Аппроксимация частотной зависимости магнитной восприимчивости}

В этом разделе рассмотрим аппроксимацию частотной зависимости магнитной восприимчивости, причем будем учитывать, что эта зависимость описывается релаксацией не одного осциллятора, как в формуле (1), а набором осцилляторов с некоторым распределением частот. Эта частотная зависимость описывается формулой КоулКоула для релаксирующих осцилляторов [16]:

$$
\dot{\chi}(\omega)=\chi^{\prime}(\omega)-i \chi^{\prime \prime}(\omega)=\chi_{\infty}+\frac{\chi_{0}-\chi_{\infty}}{1+(i \omega \tau)^{1-\alpha}},
$$

где $0 \leq \alpha \leq 1$. В формуле (2) $\tau$ - это среднее время релаксации распределения осцилляторов, $\alpha-$ подгоночный параметр, связанный с шириной спектра частот осцилляторов. Распределение спектра осцилляторов характеризуется наличием времени отсечки $\tau_{c}$ и протяжением спектра в область меньших времен. Вид функции распределения осцилляторов приведен в $[17,12]$. В случае одного релаксирующего осциллятора, либо очень узкого распределения времен релаксации нескольких осцилляторов, т. е. при $\alpha \approx 0$, формула (2) переходит в формулу распределения Дебая. Как указывается в [5], для материалов типа спинового льда при $T<2 \mathrm{~K}$ под временем $\tau$ нужно понимать время релаксации магнитных монополей. В $[5,18]$ с использованием данных о температурной зависимости удельной теплоемкости и восприимчивости $\chi_{0}$, была построена температурная зависимость подвижности монополей. Время отсечки $\tau_{c}$ в модели спинового льда связывается с процессами торможения и захвата магнитных монополей. В нашей работе, выполненной для нанокомпозитов с частицами $\mathrm{Dy}_{2} \mathrm{Ti}_{2} \mathrm{O}_{7}$ и $\mathrm{Dy}_{2} \mathrm{Si}_{2} \mathrm{O}_{7}, \mathrm{Gd}_{2} \mathrm{Ti}_{2} \mathrm{O}_{7}$ при более высоких температурах и не в состоянии спинового льда, под $\tau$ нужно понимать время релаксации, которое определяется другими механизмами релаксации спинов. В частности, релаксация при температурах $\sim 10 \mathrm{~K}$ связана с переворотом спина редкоземельных ионов при переходе между двумя уровнями в дублете основного состояния [19].

Обобщение формулы (2) можно представить в виде

$$
\dot{\chi}(\omega)=\sum_{k=1}^{K}\left(\chi_{k}^{\infty}+\frac{\chi_{k}^{0} \chi_{k}^{\infty}}{1+\left(i \omega \tau_{k}\right)^{1-\alpha_{k}}}\right),
$$

который соответствует модели с $K$ временами релаксации $\tau_{k}$, около которых сосредоточены распределения времен релаксации. Далее мы выясним возможность удовлетворительной аппроксимации частотной зависимости магнитной восприимчивости нанокомпозитных титанатов с частицами $\mathrm{Gd}_{2} \mathrm{Ti}_{2} \mathrm{O}_{7}$. 
Параметры аппроксимации частотной зависимости восприимчивости

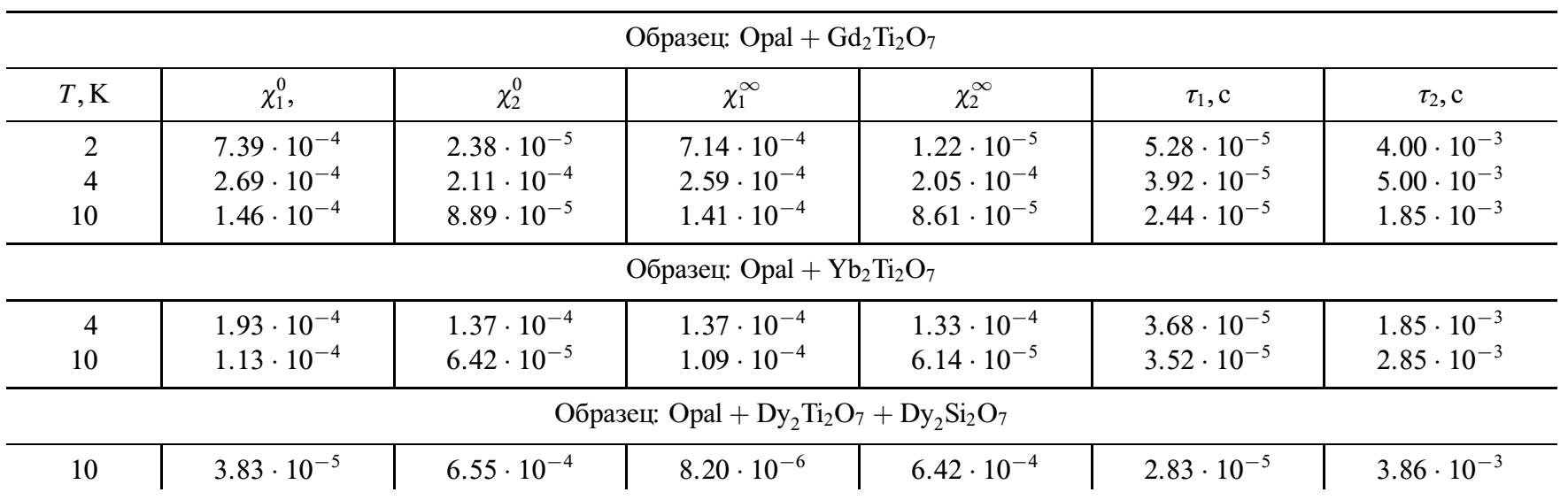

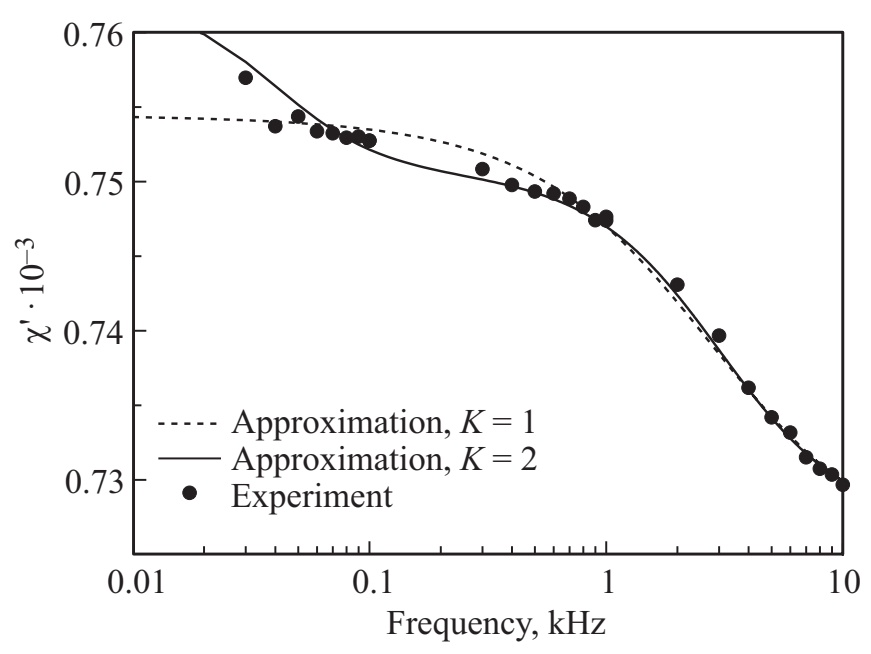

Рис. 8. Частотная зависимость действительной части АС восприимчивости для образца нанокомпозита с частицами $\mathrm{Gd}_{2} \mathrm{Ti}_{2} \mathrm{O}_{7}$ при $T=2 \mathrm{~K}$ и результаты ее аппроксимации с использованием формул (2) и (3).

На рис. 8 показаны результаты аппроксимации по формулам (2) и (3) действительной части магнитной восприимчивости для нанокомпозитного материала с частицами титаната гадолиния при $T=2 \mathrm{~K}$. Символами обозначены измеренные экспериментально значения, а линиями - аппроксимация. Как можно видеть, для частот свыше $1-1.5 \mathrm{kHz}$ аппроксимация с одним временем релаксации достаточно хорошо соответствует результатам измерений. При более низких частотах наблюдается существенное отклонение от зависимости, предписанной формулами (1) и (2). Использование модели с двумя временами релаксации спинов позволяет осуществить вполне хорошую аппроксимацию. Времена релаксации, полученные в результате аппроксимации, приведены в таблице. Следует заметить, что рассматриваемый титанат $\mathrm{Gd}_{2} \mathrm{Ti}_{2} \mathrm{O}_{7}$ не обладает свойствами „спинового льда“, так что механизмы релаксации спинов не связаны с переходом в это состояние.
На рис. 9 показана частотная зависимость действительной части $\mathrm{AC}$ восприимчивости $\chi^{\prime}(\omega)$ для образца нанокомпозита с частицами $\mathrm{Dy}_{2} \mathrm{Ti}_{2} \mathrm{O}_{7}$ и $\mathrm{Dy}_{2} \mathrm{Si}_{2} \mathrm{O}_{7}$ при $T=10 \mathrm{~K}$ и результаты ее аппроксимации. Для удобства сравнения по оси $\mathrm{X}$ выбран логарифмический масштаб. Видно, что использование модели с двумя временами релаксации по формуле (3) дает намного лучшее описание частотной зависимости. Важно отметить, что формулы (1) или (2) не могут описать хода частотной зависимости действительной части восприимчивости нанокомпозитных редкоземельных титанатов во всем частотном интервале $1 \mathrm{~Hz}<f<1 \mathrm{kHz}$. Поэтому оправданно и необходимо применение модели осцилляторов с двумя временами релаксации.

В таблице приведены численные значения параметров аппроксимации для нанокомпозитов с частицами $\mathrm{Gd}_{2} \mathrm{Ti}_{2} \mathrm{O}_{7}, \mathrm{Yb}_{2} \mathrm{Ti}_{2} \mathrm{O}_{7}$ и $\left(\mathrm{Dy}_{2} \mathrm{Ti}_{2} \mathrm{O}_{7}+\mathrm{Dy}_{2} \mathrm{Si}_{2} \mathrm{O}_{7}\right)$. Из этих данных следует, что времена релаксации $\tau_{1}$, определенные из частотной зависимости действительной части АС

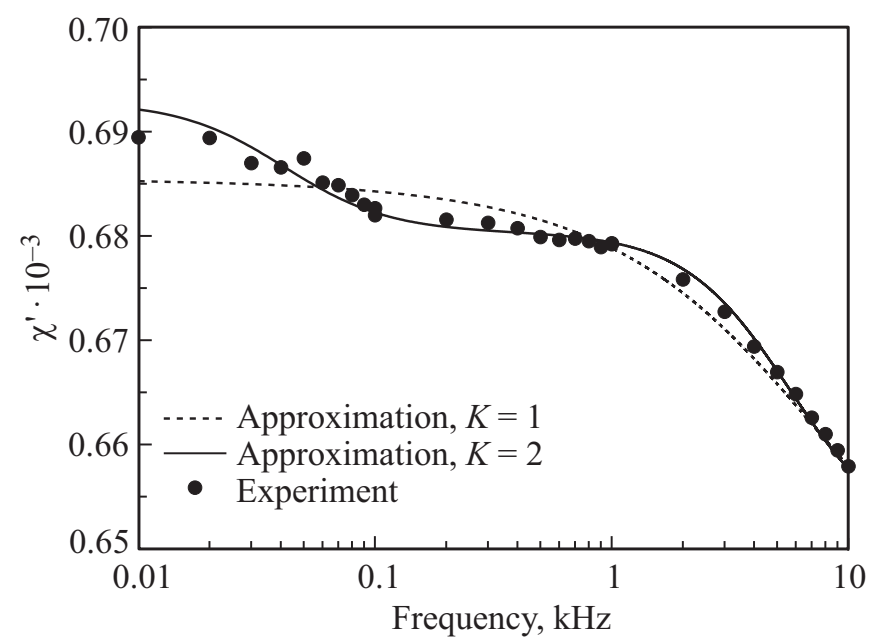

Pис. 9. Частотная зависимость действительной части АC восприимчивости для образца нанокомпозита с частицами $\mathrm{Dy}_{2} \mathrm{Ti}_{2} \mathrm{O}_{7}$ и $\mathrm{Dy}_{2} \mathrm{Si}_{2} \mathrm{O}_{7}$ при $T=10 \mathrm{~K}$ и результаты ее аппроксимации с использованием формул (2) и (3). 
восприимчивости, составляют несколько десятков микросекунд, а времена $\tau_{2}$ примерно в $80-100$ раз больше. С повышением температуры оба времени релаксации уменьшаются для всех исследованных нанокомпозитов. Для сравнения можно привлечь данные о магнитной релаксации в объемных образцах титаната $\mathrm{Dy}_{2} \mathrm{Ti}_{2} \mathrm{O}_{7}[12]$. В этой работе используется представление о двух временах магнитной релаксации, причем при температуре $T=2$ К эти времена имеют порядок величины $10^{-4}$ и $10^{-3}$ s. C увеличением температуры в [12] время релаксации уменьшается, как и у нас для нанокомпозитного образца.

Относительно восприимчивостей при $\omega \rightarrow 0 \quad \chi_{1}^{0}, \chi_{2}^{0}$ (т. е. „префакторов“) можно сказать следующее. Для нанокомпозитов с частицами $\mathrm{Gd}_{2} \mathrm{Ti}_{2} \mathrm{O}_{7}, \mathrm{Yb}_{2} \mathrm{Ti}_{2} \mathrm{O}_{7} \chi_{1}^{0}>\chi_{2}^{0}$, a для нанокомпозита с частицами $\mathrm{Dy}_{2} \mathrm{Ti}_{2} \mathrm{O}_{7}$ и $\mathrm{Dy}_{2} \mathrm{Si}_{2} \mathrm{O}_{7}$ наоборот, $\chi_{1}^{0}<\chi_{2}^{0}$. С ростом температуры оба префактора $\chi_{1}^{0}$ и $\chi_{2}^{0}$ уменьшаются. Параметр $\alpha_{1}$ для нанокомпозитов оказался $\sim 0.1$, а параметр $\alpha_{2} \sim 0.01$, что значительно меньше единицы. Отсюда можно сделать вывод, что на частотах свыше $1 \mathrm{kHz}$, где основной вклад в АС восприимчивость дает процесс релаксации с первым временем релаксации, модель релаксации Дебая (1) вполне применима.

\section{5. Заключение}

Проведено экспериментальное исследование магнитной восприимчивости нанокомпозитных редкоземельных титанатов типа $R_{2} \mathrm{Ti}_{2} \mathrm{O}_{7}$ при низких температурах в интервале частот от 1 до $10 \mathrm{kHz}$. Использованы нанокомпозиты на основе опаловых матриц, в межсферические полости которых помещены частицы титанатов размером до $60 \mathrm{~nm}$. Исследованы нанокомпозиты с частицами титанатов $\mathrm{Gd}_{2} \mathrm{Ti}_{2} \mathrm{O}_{7}, \mathrm{Yb}_{2} \mathrm{Ti}_{2} \mathrm{O}_{7}, \mathrm{Dy}_{2} \mathrm{Ti}_{2} \mathrm{O}_{7}$ и $\mathrm{Dy}_{2} \mathrm{Si}_{2} \mathrm{O}_{7}$.

Установлено, что в области частот свыше $1 \mathrm{kHz}$ частотная зависимость удовлетворительно описывается моделью релаксирующих осцилляторов с одним временем релаксации порядка десятков микросекунд. Параметр аппроксимации $\alpha$ при аппроксимации по формуле Коул-Коула много меньше единицы, так что частотная зависимость АС восприимчивости хорошо аппроксимируется по формуле Дебая. Для описания частотной зависимости АС восприимчивости во всем интервале $1 \mathrm{~Hz}<f<10 \mathrm{kHz}$ требуется привлечение модели релаксации с двумя временами. А в интервале температур от 2 до $10 \mathrm{~K}$ необходимо применять модель релаксации с двумя временами для всех исследованных нанокомпозитов.

\section{Благодарности}

Авторы благодарны А.В. Королеву за выполнение магнитных измерений в ЦКП ИФМ УрО РАН.

\section{Финансирование работы}

Работа выполнена в рамках госзадания по теме „Функция““ № АААА-А19-119012990095-0.

\section{Конфликт интересов}

Авторы заявляют, что у них нет конфликта интересов.

\section{Список литературы}

[1] S.T. Bramwell, M.J.P. Gingras. Science 294, 1495 (2001).

[2] K. Matsuhira, Z. Hiroi, T. Tayama, S. Takagi, T. Sakakibara. J. Phys.: Condens. Matter 14, L559 (2002).

[3] D. Slobinsky, C. Castelnovo, R.A. Borzi, A.S. Gibbs, A.P. Mackenzie, R. Moessner, S.A. Grigera. Phys. Rev. Lett. 105, 267205 (2010).

[4] C. Castelnovo, R. Moessner, S.L. Sondhi. Nature 451, 42 (2008).

[5] L. Bovo, J.A. Bloxsom, D. Prabhakaran, G. Aeppli, S.T. Bramwell. Nature Commun. 4, 1535 (2013).

[6] B.Z. Malkin, T.T.A. Lummen, P.H.M. van Loosdrecht, G. Dhalenne, A.R. Zakirov. J. Phys.: Condens. Matter. 22, 276003 (2010).

[7] J. Snyder, B.G. Ueland, J.S. Slusky, H. Karunadasa, R.J. Cava, P. Schiffer. Phys. Rev. B 69, 064414 (2004).

[8] A.B. Rinkevich, A.V. Korolev, M.I. Samoilovich, S.O. Demokritov, D.V. Perov. J. Magn. Magn. Mater. 453, 137 (2018).

[9] O.V. Nemytova, I.V. Piir, M.V. Koroleva, D.V. Perov, A.B. Rinkevich. J. Magn. Magn. Mater. 493, 165800 (2020).

[10] А.Б. Ринкевич, М.С. Королева, И.В. Пийр, Д.В. Перов. ФTT 61, 1401 (2019)

[11] K. Matsuhira, Y. Hinatsu, T. Sakakibara. J. Phys.: Condens. Matter 13, L737 (2001).

[12] K. Matsuhira, C. Paulsen, E. Lhotel, C. Sekine, Z. Hiroi, S. Takagi. J. Phys. Soc. Jpn 80, 123711 (2011).

[13] G. Ehlers, A.L. Cornelius, T. Fennell, M. Koza, S.T. Bramwell, J.S. Gardner. J. Phys.: Condens. Matter 16, (2004)

[14] A.B. Rinkevich, A.M. Burkhanov, M.I. Samoilovich, A.F. Belyanin, S.M. Kleshcheva, E.A. Kuznetsov. Russ. J. Gen. Chem. 83, 2148 (2013).

[15] M.J. Matthews, C. Castelnovo, R. Moessner, S.A. Grigera, D. Prabhakaran, P. Schiffer. Phys. Rev. B 86, 214419 (2012).

[16] K.S. Cole, R.H. Cole. J. Chem. Phys. 9, 341 (1941).

[17] D.W. Davidson, R.H. Cole. J. Chem. Phys. 18, 1417 (1950).

[18] C. Castelnovo, R. Moessner, S.L. Sondhi. Phys. Rev. B 84, 144435 (2011).

[19] G. Ehlers, A.L. Cornelius, M. Orendac, M. Kajnakova, T. Fennell, S.T. Bramwell, J.S. Gardner. J. Phys. Condens. Matter 15, L9 (2003)

Редактор Т.Н. Василевская 